\title{
Pulse rate variability: a new biomarker, not a surrogate for heart rate variability
}

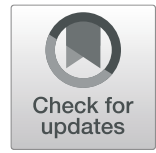

\author{
Emi Yuda', Muneichi Shibata ${ }^{2}$, Yuki Ogata ${ }^{3}$, Norihiro Ueda ${ }^{4}$, Tomoyuki Yambe ${ }^{5}$, Makoto Yoshizawa ${ }^{6}$ and \\ Junichiro Hayano ${ }^{4^{*}}$ (1)
}

\begin{abstract}
With the popularization of pulse wave signals by the spread of wearable watch devices incorporating photoplethysmography (PPG) sensors, many studies are reporting the accuracy of pulse rate variability (PRV) as a surrogate of heart rate variability (HRV). However, the authors are concerned about their research paradigm based on the assumption that PRV is a biomarker that reflects the same biological properties as HRV. Because PPG pulse wave and ECG R wave both reflect the periodic beating of the heart, pulse rate and heart rate should be equal, but it does not guarantee that the respective variabilities are also the same. The process from ECG $R$ wave to PPG pulse wave involves several transformation steps of physical properties, such as those of electromechanical coupling and conversions from force to volume, volume to pressure, pressure impulse to wave, pressure wave to volume, and volume to light intensity. In fact, there is concreate evidence that shows discrepancy between PRV and HRV, such as that demonstrating the presence of PRV in the absence of HRV, differences in PRV with measurement sites, and differing effects of body posture and exercise between them. Our observations in adult patients with an implanted cardiac pacemaker also indicate that fluctuations in R-R intervals, pulse transit time, and pulse intervals are modulated differently by autonomic functions, respiration, and other factors. The authors suggest that it is more appropriate to recognize PRV as a different biomarker than HRV. Although HRV is a major determinant of PRV, PRV is caused by many other sources of variability, which could contain useful biomedical information that is neither error nor noise.
\end{abstract}

Keywords: Pulse wave, Photoplethysmography, Heart rate, Heart rate variability

\section{Main text}

Recently, many studies have reported the accuracy of pulse rate variability (PRV) as a surrogate of heart rate variability (HRV) [1-4]. Since photoplethysmography (PPG) sensors are almost universally incorporated into the widespread wearable watch devices, the pulse wave has become the most popular biosignal available in daily life, replacing electrocardiogram (ECG). Therefore, it may be natural to consider the use of PRV to assess

\footnotetext{
* Correspondence: hayano@acm.org

${ }^{4}$ Nagoya City University Graduate School of Medical Sciences, Kawasumi 1 Mizuho-cho Mizuho-ku, Nagoya 467-8602, Japan

Full list of author information is available at the end of the article
}

autonomic functions and disease prognosis in the same way as HRV. However, the authors are concerned about the research paradigm based on the assumption that PRV is a biomarker that reflects the same biological properties as HRV.

This assumption could undermine the physiological and pathological value of PRV. Both PPG pulse wave and ECG $\mathrm{R}$ wave reflect the periodic beating of the heart. Thus, without cardiac electromechanical dissociation, pulse rate and heart rate should be equal, but it does not guarantee that the respective variabilities are also the same. As shown in Table 1, the process beginning with ECG $R$ wave and ending with PPG pulse wave 
Table 1 Factors affecting the information transmission from ECG R wave to PPG pulse wave

\begin{tabular}{|c|c|c|c|c|}
\hline \multirow{2}{*}{$\begin{array}{l}\text { Physiological } \\
\text { measure }\end{array}$} & \multirow{2}{*}{$\begin{array}{l}\text { Anatomical } \\
\text { location }\end{array}$} & \multirow{2}{*}{$\begin{array}{l}\text { Conversion } \\
\text { of physical } \\
\text { property }\end{array}$} & \multicolumn{2}{|l|}{ Modulators } \\
\hline & & & Direct & Indirect \\
\hline $\begin{array}{l}\text { ECG R wave } \\
\downarrow\end{array}$ & $\begin{array}{l}\text { Left ventricular } \\
\text { muscle }\end{array}$ & $\begin{array}{l}\text { Electric } \\
\text { excitation } \\
\downarrow\end{array}$ & $\begin{array}{l}\text { Intraventricular conduction, ventricular } \\
\text { activation time, electromechanical coupling }\end{array}$ & Myocardial ischemia, heart diseases \\
\hline $\begin{array}{l}\text { Pre-ejection } \\
\text { period } \\
\downarrow\end{array}$ & Left ventricle & $\begin{array}{l}\text { Muscle } \\
\text { force } \\
\downarrow\end{array}$ & $\begin{array}{l}\text { Preload and after-load, contractility, aortic dia- } \\
\text { stolic pressure }\end{array}$ & $\begin{array}{l}\text { Respiration, blood pressure, body position and } \\
\text { exercise, heart failure (alternating pulse) }\end{array}$ \\
\hline $\begin{array}{l}\text { Aortic } \\
\text { pressure } \\
\text { elevation } \\
\downarrow\end{array}$ & Aorta & $\begin{array}{l}\text { Pressure } \\
\text { impulse } \\
\downarrow\end{array}$ & $\begin{array}{l}\text { Stroke volume, aortic dynamic compliance, } \\
\text { intrathoracic pressure }\end{array}$ & Respiration, peripheral resistance \\
\hline $\begin{array}{l}\text { Pulse } \\
\text { conduction } \\
\text { time } \\
\downarrow\end{array}$ & Artery & $\begin{array}{l}\text { Pressure } \\
\text { wave } \\
\downarrow\end{array}$ & $\begin{array}{l}\text { Internal radius, wall thickness and elasticity, } \\
\text { blood density }\end{array}$ & $\begin{array}{l}\text { Vasomotor sympathetic activity, endothelial } \\
\text { function, blood pressure }\end{array}$ \\
\hline $\begin{array}{l}\text { Tissue volume } \\
\downarrow\end{array}$ & $\begin{array}{l}\text { Tissue } \\
\text { microvasculature }\end{array}$ & $\begin{array}{l}\text { Blood } \\
\text { volume } \\
\downarrow\end{array}$ & $\begin{array}{l}\text { Vascular dynamic compliance, blood flow, } \\
\text { venous pressure }\end{array}$ & $\begin{array}{l}\text { Location and body position, body and } \\
\text { environmental temperature }\end{array}$ \\
\hline $\begin{array}{l}\text { PPG pulse } \\
\text { wave }\end{array}$ & $\begin{array}{l}\text { Red cell } \\
\text { hemoglobin }\end{array}$ & $\begin{array}{l}\text { Light } \\
\text { intensity }\end{array}$ & $\begin{array}{l}\text { Absorption, scattering, reflection, and } \\
\text { transmission; vascular bed volume }\end{array}$ & $\begin{array}{l}\text { Local red cell count, hemoglobin content, } \\
\text { waveform fiducial point }\end{array}$ \\
\hline
\end{tabular}

ECG electrocardiography, PPG Photoplethysmography

involves several steps of the transformation of physical properties. First, ECG R wave is electric potential caused by depolarization of ventricular myocytes, which triggers the contraction of the myocardium (electromechanical coupling). Second, ventricular wall contraction increases left ventricular pressure (force-pressure conversion), which opens the aortic valve when it exceeds the diastolic aortic pressure (the time up to this step is preejection period). Third, the left ventricle propels the volume of blood (corresponding to stroke volume) during the opening of the aortic valve, which causes pressure impulse according to its compliance in the aorta (volume-pressure conversion). Forth, the pressure impulse generates a pulse wave, which conducts through the arterial wall at a velocity determined by the arterial radius, wall thickness, and elasticity and blood density (impulse-wave conversion). Fifth, the pulse wave reached the site of PPG measurement in pulse conduction time and increases blood volume in the tissue vascular bed (pressure-volume conversion). Finally, the changes in blood volume cause changes in reflected/transmitted light intensity, which are detected by the PPG sensors (volume-light intensity conversion). Each of these six steps has a respective transfer function with different delays and frequency characteristics, and various factors, such as autonomic activities, respiration, blood pressure, and diseases, could modulate those functions directly and indirectly and also generate the intrinsic components of PRV.

In fact, there is concrete evidence of the dissociation between PRV and HRV. Constant et al. [5] reported the presence of PRV in the absence of HRV in pediatric patients with a fixed-rate implanted pacemaker. Wong et al. [6] observed differences not only between PRV and HRV but also between PRV measured from the fingers of the right and left hands. We also observed the differences in PRV measured on the forearm and wrist even in the same arm [7]. Additionally, differing effects of body posture and exercise between PRV and HRV [8] and the variance of PRV caused by the effects of differing waveform on pulse wave fiducial point have been reported $[9,10]$.

Following a pioneering work by Constant et al. [5] in children, we recorded PPG simultaneously with ECG in an elderly female patient with fixed-rate ventricular pacing (Fig. 1). Despite the absent HRV and its flat power spectrum (panels a and e), fluctuations were observed in the pulse transit time (PTT) measured as the time from the ECG $\mathrm{R}$ wave to the PPG presystolic foot point (pre-ejection period plus pulse conduction time) (panel b). Additionally, the power spectrum of PTT had two major peaks at 0.07 and $0.22 \mathrm{~Hz}$, corresponding to low-frequency (LF) and high-frequency (HF) components, respectively (panel f). This suggests that any or all of the steps comprising PTT are subject to autonomic, respiratory, and other modulations. Pulse interval also showed fluctuations, i.e., PRV (panel c), but its power spectrum had only HF peak but not LF (panel g). The absent LF in PRV is reflected in lower coherence and transfer magnitude for the LF band of the transfer function from PTT to pulse interval (panel j). Theoretically, when pulse signals with a constant interval at $860 \mathrm{~ms}$ are transmitted with a transit time that oscillates at $0.07 \mathrm{~Hz}$, 

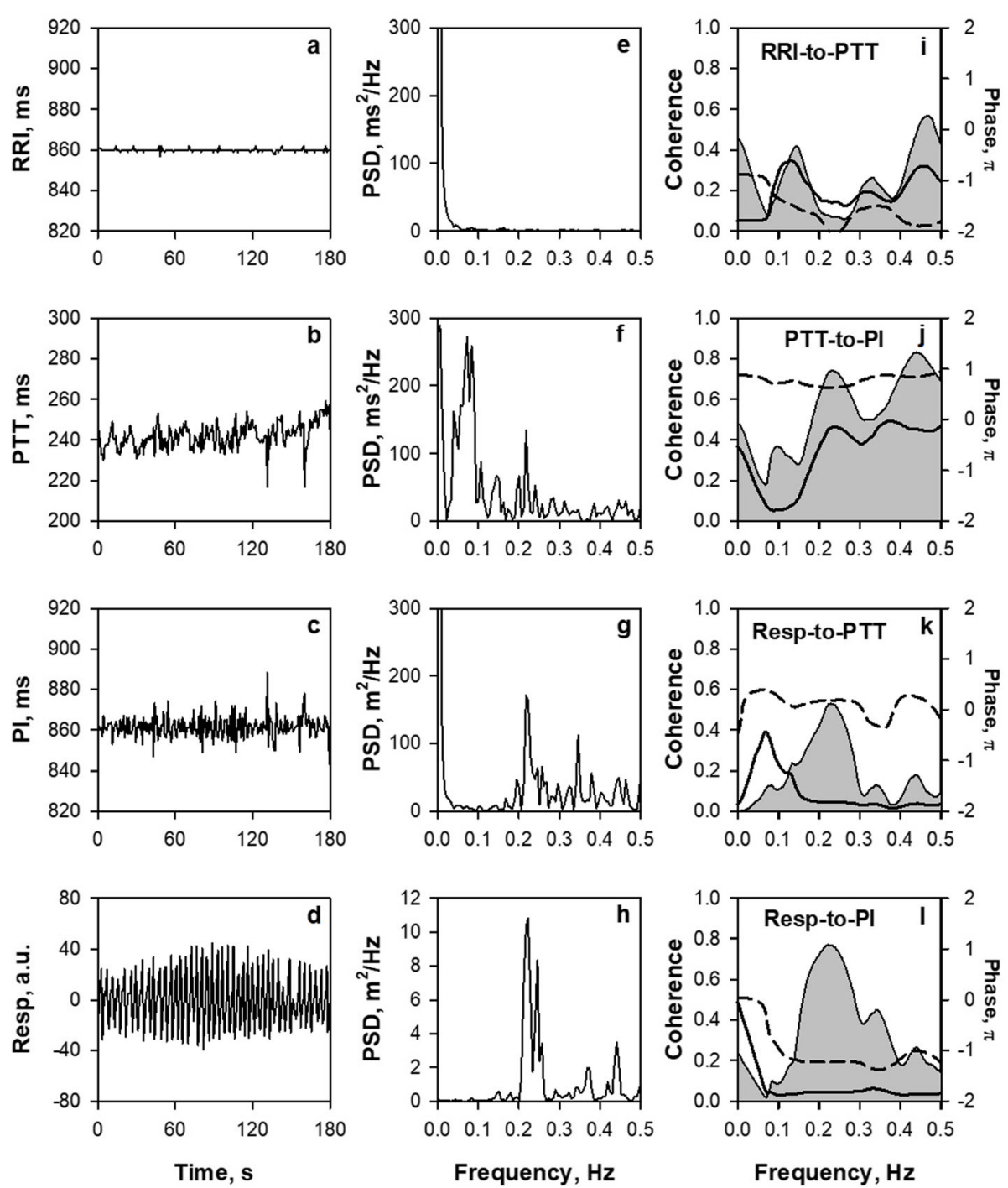

Fig. 1 Spectrum and cross-spectrum analyses of R-R interval (RRI), pulse transit time (PTT), pulse interval (PI), and respiration (Resp) measured from simultaneous recordings of ECG, finger-tip photoplethysmography (PPG), and nose-tip thermistor respiration in a female patient (91 year) with an implanted cardiac pacemaker with a fixed pacing rate $(70 \mathrm{bpm})$. All signals were recorded at $1000 \mathrm{~Hz}$. PTT was measured as time from ECG R wave to PPG presystolic foot point of each beat and PI as the interval between the foot points of consecutive beats. In panels $\mathbf{i}-\mathbf{I}$, shadowed area, solid line, and dashed line represent coherence, transfer magnitude, and phase, respectively. PSD, power spectral density

pulse signals observed at the transmission destination show interval variations with a power of 0.14 times the transit time oscillation. Conversely, when the transit time oscillates at $0.22 \mathrm{~Hz}$, the power of the observed pulse signal interval variation is amplified 1.25 times, and when it oscillates at $0.3 \mathrm{~Hz}$, the power is amplified 2.0 times the transit time oscillation. This indicates that the higher the PTT fluctuation frequency, the more amplified power the PRV is generated. This suggests that the mechanisms of increased PRV HF power during standing and exercise $[3,8]$ may be attributable at least partly to an increase in respiratory frequency. These phenomena indicate that fluctuations could be generated and modulated by autonomic functions, respiration, and other factors differently in R-R intervals, PTT, and pulse intervals, suggesting that PRV is a signal containing the physiological and pathological information that is not contained in HRV.

\section{Conclusions}

The authors suggest that it is more appropriate to recognize PRV as a biomarker different from HRV. Although HRV is a major source of PRV, PRV is generated and modulated by many other sources and factors, which could contain useful biomedical information that is neither error nor noise. From this aspect, there seem 
more valuable approaches than pursuing the accuracy of PRV as a surrogate for HRV. One is to analyze HRV and PRV simultaneously to find physiological and clinical values of their differences in time and frequency domains and nonlinear dynamics, i.e., the noninvasive analyses of dynamic conduction properties of impulse train generated by the heart. The other is to directly investigate the biomedical usefulness of PRV itself, independent of HRV.

\section{Abbreviations}

ECG: Electrocardiogram; HRV: Heart rate variability;

PPG: Photoplethysmography; PRV: Pulse rate variability

\section{Acknowledgements}

Not applicable.

\section{Authors' contributions}

EY: concept/design, data interpretation, critical revision of article, and approval of article. MS: data collection, data analysis, and approval of article. YO: data collection, data analysis, and approval of article. NU: data interpretation, critical revision of article, and approval of article. TY: data interpretation and approval of article. MY: concept/design and approval of article. $\mathrm{JH}$ : concept/design, data interpretation, drafting article, and approval of article.

\section{Funding}

Not applicable.

\section{Availability of data and materials}

The datasets used for the current study are available from the corresponding author on reasonable request.

\section{Ethics approval and consent to participate}

All subjects gave their written informed consent to participate in this study. The study was performed according to the protocol approved by the Makabe Hospital Ethics Committee (No. 201902).

\section{Consent for publication}

Not applicable.

\section{Competing interests}

The authors declare that they have no competing interests.

\section{Author details}

${ }^{1}$ Department of Electrical Engineering, Graduate School of Engineering, Tohoku University, Sendai, Japan. ${ }^{2}$ Cardiology, Mackay Base Hospital, Mackay, Australia. ${ }^{3}$ Makabe Hospital, Higashi Matsushima, Miyagi, Japan. ${ }^{4}$ Nagoya City University Graduate School of Medical Sciences, Kawasumi 1 Mizuho-cho Mizuho-ku, Nagoya 467-8602, Japan. ${ }^{5}$ Institute of Development, Aging and Cancer, Tohoku University, Sendai, Japan. ${ }^{6}$ Research Division on Advanced Information Technology, Cyberscience Center, Tohoku University, Sendai, Japan.

Received: 7 July 2020 Accepted: 3 August 2020

Published online: 18 August 2020

\section{References}

1. Selvaraj N, Jaryal A, Santhosh J, Deepak KK, Anand S. Assessment of heart rate variability derived from finger-tip photoplethysmography as compared to electrocardiography. J Med Eng Technol. 2008;32(6):479-84.

2. Lu G, Yang F, Taylor JA, Stein JF. A comparison of photoplethysmography and ECG recording to analyse heart rate variability in healthy subjects. J Med Eng Technol. 2009;33(8):634-41.

3. Gil E, Orini M, Bailon R, Vergara JM, Mainardi L, Laguna $P$. Photoplethysmography pulse rate variability as a surrogate measurement of heart rate variability during non-stationary conditions. Physiol Meas. 2010; 31(9):1271-90.
4. Weinschenk SW, Beise RD, Lorenz J. Heart rate variability (HRV) in deep breathing tests and 5-min short-term recordings: agreement of ear photoplethysmography with ECG measurements, in 343 subjects. Eur J Appl Physiol. 2016;116(8):1527-35.

5. Constant I, Laude D, Murat I, Elghozi JL. Pulse rate variability is not a surrogate for heart rate variability. Clin Sci (Lond). 1999;97(4):391-7.

6. Wong JS, Lu WA, Wu KT, Liu M, Chen GY, Kuo CD. A comparative study of pulse rate variability and heart rate variability in healthy subjects. J Clin Monit Comput. 2012;26(2):107-14.

7. Yuda E, Yamamoto K, Yoshida Y, Hayano J. Differences in pulse rate variability with measurement site. J Physiol Anthropol. 2020;39(1):4.

8. Charlot K, Cornolo J, Brugniaux JV, Richalet JP, Pichon A. Interchangeability between heart rate and photoplethysmography variabilities during sympathetic stimulations. Physiol Meas. 2009;30(12):1357-69.

9. Peng $\mathrm{RC}$, Zhou XL, Lin WH, Zhang YT. Extraction of heart rate variability from smartphone photoplethysmograms. Comput Math Methods Med. 2015;2015:516826.

10. Rapalis A, Petrenas A, Simaityte M, Bailon R, Marozas V. Towards pulse rate parametrization during free-living activities using smart wristband. Physiol Meas. 2018:39(5):055007.

\section{Publisher's Note}

Springer Nature remains neutral with regard to jurisdictional claims in published maps and institutional affiliations.
Ready to submit your research? Choose BMC and benefit from:

- fast, convenient online submission

- thorough peer review by experienced researchers in your field

- rapid publication on acceptance

- support for research data, including large and complex data types

- gold Open Access which fosters wider collaboration and increased citations

- maximum visibility for your research: over $100 \mathrm{M}$ website views per year

At $\mathrm{BMC}$, research is always in progress.

Learn more biomedcentral.com/submissions 